\title{
Política industrial: uma visão Neo-Schumpeteriana Sistêmica e Estrutural
}

\author{
Industrial policy: a systemic and structural \\ New-Shumpeterian vision
}

CARLOS AUGUSTO GRABOIS GADELHA*,**

RESUMO: Este artigo desenvolve uma visão neo-Schumpeteriana da política industrial, tentando superar os focos trabalhados pela teoria econômica convencional. Mostra a inadequação da distinção sugerida pelas abordagens que privilegiam a dimensão horizontal e pelas que defendem uma concepção seletiva da política industrial. A intervenção estatal na dinâmica de inovações da indústria deve ser, simultaneamente, sistêmica e estrutural, privilegiando a ação estatal nas interdependências sistêmicas específicas em relação às diferentes indústrias. Assim sendo, a política industrial sistêmica envolve opções, cuja definição depende dos requisitos peculiares de competitividade da estrutura industrial efetiva e desejada. PALAVRAS-CHAVE: Política industrial; análise neo-shumpeteriana; inovação; competição.

ABSTRACT: This article develops a neo-Schumpeterian vision of industrial policy, trying to overcome the focuses worked by the conventional economic theory. It shows the inadequacy of the distinction suggested by the approaches that privilege the horizontal dimension and the ones that plead a selective conception of the industrial politics. The state intervention in the innovations dynamics of the industry should be, simultaneously, systemic and structural, privileging the state action in the systemic interdependences that are specific in relation to the different industries. Like this being, the systemic industrial policy involves options, whose definition depends on the peculiar requirements of competitiveness of the effective and desired industrial structure.

KEYWORDS: Industrial policy; neo-Schumpeterian analysis; innovation; competition.

JEL Classification: L52; B52.

* professor do Departamento de Administração e Planejamento da Escola Nacional de Saúde Pública da Fundação Oswaldo Cruz, São Paulo/SP, Brasil. E-mail: carlos.gadelha@fiocruz.br.

* * Doutor em Economia pelo Departamento de Administração e Planejamento da Escola Nacional de Saúde Pública da Fundação Oswaldo Cruz, onde desenvolve linhas de pesquisa sobre Estado e Inovação. Trabalho baseado na Tese de Doutorado do autor. 
Objetiva-se neste artigo desenvolver uma concepção neo-schumpeteriana de política industrial, procurando retomar a tradição estruturalista com base num aparato conceituai vigoroso e alternativo ao neoclássico. No primeiro tópico, de caráter introdutório, procura-se situar o contexto analítico em que a proposta de política industrial é desenvolvida, fazendo uma breve discussão crítica dos conceitos usuais de política industrial utilizados na literatura econômica e localizando a política industrial no contexto mais amplo das políticas nacionais de desenvolvimento. No tópico 2, são explicitados os desdobramentos do enfoque neo-schumpeteriano sobre a dinâmica econômica para a visão de política industrial desenvolvida, propondo-se uma orientação sistêmica e estrutural. No tópico 3, são demarcados os horizontes temporais que permeiam as estratégias de política industrial aos quais correspondem critérios normativos e padrões de intervenção diferenciados. Por fim, no último tópico, são efetuadas considerações sobre aspectos metodológicos e teóricos que nortearam a análise desenvolvida, demarcando algumas de suas contribuições principais.

\section{INTRODUÇÃO}

Antes de avançar no enfoque de política industrial que será desenvolvido neste trabalho, procura-se fazer, neste tópico, duas demarcações preliminares que permitem situar a proposta apresentada. Em primeiro lugar, trata-se de situar a contribuição conceitual pretendida frente às visões teóricas hegemônicas sobre o assunto, que se mostram insuficientes ou limitadas. Em segundo lugar, já no processo de construção de uma visão alternativa, procura-se situar a política industrial no contexto mais amplo das políticas econômicas, especificando, em particular, sua localização no contexto das políticas nacionais de desenvolvimento.

\section{Conceitos Tradicionais de Política Industrial}

O conceito de política industrial tem sido tradicionalmente trabalhado a partir de dois enfoques polares (Suzigan \& Villela, 1997). O primeiro, mais amplo e normalmente classificado como horizontal ou sistêmico, enfatiza a ação governa mental sobre as condições gerais que conformam o ambiente econômico, interferindo no desenvolvimento industrial de forma indireta. Nesse enfoque, a política industrial envolve as orientações para as condições de infraestrutura física, educacional e de ciência e tecnologia (C\&T), a política antitruste, as diretrizes governamentais mais gerais para a indústria e até mesmo a política macroeconômica, entre outros aspectos que interferem de forma importante, porém indistinta, sobre o setor industrial. A ação seletiva para indústrias particulares é descartada ou, no máximo, é vista como um componente adicional da política industrial, cujo impacto é considerado restrito e pertinente somente em condições econômicas e institucionais muito peculiares (na linha proposta pelo BIRD, 1993 e 1997). A citação 
abaixo de um autor clássico no tratamento do tema reflete apropriadamente esta visão:

"[...] the best industrial policy may be to provide an adequate infrastructure, some limits on the power of monopolies and cartels, an education system that helps to generate the human capital for industrial success, indicative guidance about industrial prospects (without compulsion or subsidies), stability and simplicity in the system of taxation, a free and flexible capital market and a steady movement towards zero sectional protection, whether direct and indirect" (Corden, 1980, pp.182-3).

O segundo enfoque, mais restrito, associa-se às políticas seletivas verticais, vinculadas a metas para os diferentes setores da indústria (industrial targeting) que norteiam a utilização dos diversos instrumentos de estímulos e de sanções. Mesmo reconhecendo a interdependência entre as distintas políticas, esse enfoque privilegia a delimitação de um espaço próprio para a política industrial. Chang (1994) é um dos autores que procura delimitar o espaço particular da política industrial de forma mais evidente, excluindo de seu escopo as dimensões sistêmicas mais gerais, se bem que tendo a preocupação de relacionar as políticas para os setores específicos com o desempenho econômico global. O trecho abaixo permite precisar o enfoque restrito de política industrial:

"[...] defending industrial policy is not to include in it everything that is good for industrial development, but to narrow its definition [...] We propose to define industrial policy as a policy aimed at particular industries (and firms as their components) to achieve the outcomes that are perceived by the state to be efficient for the economy as a whole. This definition is close to what is usually called 'selective industrial policy $[\ldots] " '($ p. 60)

Esse último enfoque tem sido considerado pelas correntes liberais hegemônicas, tanto no campo da ciência econômica quanto no político, como típico do antigo, e obsoleto, padrão de intervenção estatal, constituindo-se numa interferência indevida nas forças de mercado. No âmbito da OECD, o relatório anual de política industrial de 1992 (que constitui o documento que marca o posicionamento político da organização desde então) expressa de forma nítida a visão hegemônica sobre o tema:

"Industrial policy in the OECD countries is at a cross-roads. It has gradually moved away from the philosophy and practices that prevailed in past decades, when it mainly consisted of measures in support of industries in decline or aimed at stimulating promising activities by 'picking winners'. A certain convergence has now been reached around a set of principles that broadly favour policy measures which do not interfere with the market process directly and instead attempt to improve its mechanisms. Such 
policies tend to be of a horizontal nature; they are market-correcting or market-enhancing, aimed directly at specific and known market flaws, or at promoting industry generally, and in particular the (labour and infrastructural) inputs available to industry" (OECD, 1992, p. 11). ${ }^{1}$

Há, assim, uma polarização das visões de política industrial entre abordagens que privilegiam ações horizontais (às vezes definidas, imprecisamente, como macroeconômicas ou sistêmicas) associadas a um padrão genérico e indireto de intervenção e outras que privilegiam a instância microeconômica setorial, envolvendo uma intervenção mais direta, seletiva e orientada por metas precisas, enfatizando o papel do Estado na escolha dos setores (e, muitas vezes, empresas) que devem elevar ou reduzir sua participação na estrutura econômica. A primeira visão, a despeito de apontar fatores centrais que interferem no ambiente que condiciona a dinâmica industrial, mostra-se pouco precisa na delimitação do objeto particular da política industrial e desconsidera os condicionantes impostos pela especificidade da estrutura produtiva e tecnológica, podendo mesmo levar ao questionamento da existência de um âmbito próprio da política industrial no contexto mais geral da política econômica. A segunda visão, por sua vez, delimita de forma mais precisa o âmbito da política industrial, porém, envolve uma perda em termos de sua relevância diante da realidade, uma vez que condicionantes não restritos à órbita setorial stricto sensu deixam de ser considerados, prejudicando os desdobramentos de uma visão sistémica do processo de inovação que enfatiza a complexidade do ambiente em que as empresas estão imersas.

É importante ainda notar que a polarização mencionada também aparece, ao menos de forma implícita, no interior do grupo dos autores neo-Schumpeterianos. Enquanto, possivelmente, a maior parte dos autores (a começar por Nelson \& Winter, 1982, além de muitos outros como Metcalfe 1995; Mowery, 1995; Ostry \& Nelson, 1995) são mais incisivos na refutação de uma ação do Estado mais seletiva e discricionária sobre a dinâmica econômica no nível dos setores ou tecnologias particulares, advogando uma ação mais genérica e horizontal, outros (como Dosi et alii, 1990; Soete, 1991; e Freeman, 1995) posicionam-se de forma menos restritiva acerca da ação seletiva e estruturante do Estado, com ênfase nas situações de atraso econômico.

A ideia defendida neste trabalho é que a mencionada polarização mostra-se inadequada para o enquadramento conceitual da política industrial, sendo necessário um aprofundamento da perspectiva neo-Schumpeteriana, sem o que suas proposições acabam se limitando aos termos do debate existente, não havendo uma ruptura normativa correspondente à profundidade da ruptura teórica com o paradigma neoclássico. ${ }^{2} \mathrm{Na}$ perspectiva adotada, como será desenvolvido adiante, não

\footnotetext{
${ }^{1} \mathrm{Na}$ mesma direção vide BIRD (1993 e 1997).

${ }^{2} \mathrm{O}$ vigor do enfoque evolucionista, assim como a perspectiva de superação do paradigma neoclássico, são evidenciados nos trabalhos seminais de Nelson \& Winter (1982) e Dosi (1984).
} 
é possível optar por um dos polos, uma vez que se enfatiza, simultaneamente, o caráter sistêmico do ambiente empresarial e a especificidade e diversidade dos padrões evolutivos das estruturas industriais. Ou seja, coloca-se o desafio analítico de efetuar uma demarcação do espaço próprio da política industrial, considerando a diversidade setorial e o papel decisivo dos fatores sistêmicos na dinâmica industrial.

\section{Política Industrial no Contexto da Política de Desenvolvimento}

Com a finalidade de avançar na demarcação do espaço particular da política industrial, cabe, ainda, situá-la no contexto mais amplo de uma política de desenvolvimento, já tendo como premissa a fragilidade da demarcação sugerida pelos enfoques tradicionais. ${ }^{3} \mathrm{Em}$ termos gerais, o desenvolvimento econômico é um processo complexo que envolve o progresso técnico, os movimentos de expansão induzida e autônoma da demanda efetiva e a transformação das instituições (Gadelha, 1999). Nesse âmbito, o papel do Estado envolve um conjunto amplo de esferas de ação não redutíveis ao campo particular da política industrial. Portanto, a ideia de se pensar o papel particular e direto do Estado na dinâmica de transformação industrial - que, como será visto, define o conceito adotado de política industrial exige que se situe o locus da política industrial no contexto mais amplo das políticas públicas.

A distinção sugerida por Erber (1992) entre padrão de desenvolvimento $e$ padrão de industrialização contribui para efetuar a demarcação pretendida. No nível mais elevado e genérico, associado ao padrão de desenvolvimento, coloca-se o que se pode definir como a política nacional de desenvolvimento que envolve todo o conjunto de macropolíticas definidas e implementadas pelos Estados Nacionais, refletindo a existência (ou a inexistência) de uma coalizão de forças sociais e condições políticas, institucionais e administrativas (definindo as condições de governabilidade e de "governança" - Diniz, 1997 e Martins, 1995) que permitem implementar projetos nacionais de desenvolvimento. Ou seja, no nível do padrão de desenvolvimento, ganha relevo a interdependência entre as distintas esferas das políticas públicas, que, em conjunto, definem o padrão de intervenção do Estado Nacional. No nível mais específico do padrão de industrialização, emerge a política industrial, que pode ser definida como o foco da intervenção pública na dinâmica de inovações da indústria, visando promover transformações qualitativas na estrutura produtiva e o desenvolvimento das economias nacionais.

Ou seja, propõe-se situar a política industrial, no contexto complexo da política de desenvolvimento, como a política vinculada especificamente à dinâmica de um determinado conjunto de atividades (as atividades industriais) que se caracterizam como as principais responsáveis pela geração e disseminação de inovações no sistema econômico, estando relacionada, portanto, à mudança estrutural. Nesta

\footnotetext{
${ }^{3} \mathrm{O}$ conceito schumpeteriano de desenvolvimento adotado neste trabalho vincula -se às trajetórias nacionais de evolução qualitativa da estrutura econômica, não se restringindo às situações de catching up.
} 
direção, a política industrial está na raiz do papel do Estado na dinâmica econômica de longo prazo, diferenciando-se, deste modo, de outras dimensões da intervenção pública que, em conjunto, são associadas aos padrões nacionais de desenvolvimento. Mesmo reconhecendo a interdependência entre os diversos campos de intervenção pública (a exemplo da relação entre a política industrial e a política macroeconômica - Corden, 1980) e a necessidade de articulação entre eles, o âmbito da política industrial deve necessariamente ser circunscrito às ações mais diretamente ligadas à dinâmica de inovações na indústria - não se discutindo ainda se sua orientação deve ser do tipo setorial ou horizontal -, o que envolve, inexoravelmente, um corte, com algum nível de arbitrariedade, entre as ações que devem e aquelas que não devem fazer parte de seu escopo específico de preocupação. ${ }^{4}$ Deste modo, reconhece-se a ideia enfatizada por Chang (conforme a citação acima) de que é metodologicamente incorreto englobar na política industrial tudo que é importante para o setor, pois isto, provavelmente, significaria tratar todas as áreas de intervenção estatal, perdendo-se a especificidade do objeto estudado. Todavia, o ponto essencial é que não se desdobra desta afirmação a percepção de que somente as políticas seletivas setoriais devem constituir seu âmbito específico; mas sim que a política industrial deve ser entendida como um foco particular da intervenção do Estado que privilegia os requerimentos de inovações da estrutura industrial, sejam eles associados especificamente aos setores de atividade ou de abrangência superior. No nível do poder do Estado e dos diferentes atores sociais, este foco da política industrial na dinâmica de transformação da estrutura produtiva remete, como um pressuposto essencial do padrão de desenvolvimento, para a necessidade de existência de uma coalização de forças políticas que viabilizem a capacidade estatal para induzir um processo de mudança estrutural, que sempre envolve setores e agentes que elevam sua lucratividade e participação na estrutura produtiva e outros que declinam, perdendo sua importância econômica relativa. Assim sendo, no âmbito político, a política industrial pode ser vista também sob o prisma da articulação particular dos interesses que suportam a mudança estrutural no contexto dos interesses mais gerais que moldam os padrões nacionais de desenvolvimento.

\section{UM ENFOQUE SISTÊMICO E ESTRUTURAL DE POLÍTICA INDUSTRIAL}

A delimitação do conceito de política industrial efetuada no tópico anterior implica que a relação analítica crucial é a existente entre a ação do Estado mais diretamente ligada à indústria e as estratégias empresariais de inovação, supondo

\footnotetext{
${ }^{4}$ Ilustrando, o estímulo à formação de recursos humanos pode tanto fazer parte de urna política de educação, quando vinculada a urna perspectiva mais genérica de dotar o país de indivíduos mais qualificados, quanto constituir urna preocupação da política industrial para a formação de pessoas numa área tecnológica de especial interesse para certos grupos de indústrias.
} 
se a existência de uma série de precondições econômicas, políticas e institucionais mais gerais que não estão no âmbito particular da política industrial e cuja coerência constitui um determinante essencial de sua efetividade.

A análise da relação entre intervenção estatal e estratégia empresarial parte da concepção de que, numa economia capitalista, a empresa privada é o agente da dinâmica econômica, sendo a forma de organização mais adequada para a busca e a seleção de inovações. No entanto, o processo competitivo impõe limites à liberdade estratégica das empresas e condiciona seu comportamento, estabelecendo estímulos mais ou menos favoráveis ao esforço inovador. Em outras palavras, o ambiente no qual a empresa está inserida condiciona, a cada momento, suas estratégias, estabelecendo os limites factíveis de suas ações, que, por sua vez, alteram o ambiente competitivo, permitindo-se pensar no seguinte encadeamento analítico:

ambiente competitivo presente $=>$ definição do leque estratégico factível => estratégias empresariais $=>$ novo ambiente competitivo

A ação do Estado, nesse esquema simplificado, vincula-se à configuração do ambiente no qual a competição ocorre, condicionando as relações de interdependência que incidem sobre o comportamento privado e, portanto, sobre a evolução dinâmica da economia ao longo do tempo. Em suma, o foco da ação estatal no ambiente econômico pressupõe a aceitação de três premissas elementares:

- o agente da dinâmica econômica capitalista assentada nas inovações é a empresa privada, que se mostra uma instância privilegiada para a busca e a introdução de inovações no sistema econômico;

- a atuação estratégica da empresa privada é condicionada pelo ambiente competitivo institucional em que está inserida, sendo ela mesma uma instituição (e não o agente de uma racionalidade geral e abstrata); e

- o Estado, como instância de poder, constitui um agente central que possui capacidade para transformar o ambiente no qual o processo competitivo ocorre, fornecendo condições mais ou menos favoráveis às estratégias inovadoras das firmas.

Observe-se que estas premissas decorrem da natureza dos agentes do sistema capitalista e de seu caráter institucional, não se fazendo qualquer referência, mesmo que implícita, às falhas de mercado como justificativa para a ação pública. Os processos de transformação que caracterizam a dinâmica do sistema capitalista resultam, de um lado, das estratégias competitivas das empresas e, de outro lado, das estratégias públicas que incidem sobre o ambiente institucional em que as empresas se defrontam, condicionando as forças evolutivas de busca de inovações e de sua seleção pelo mercado.

$\mathrm{O}$ ambiente econômico apresenta duas propriedades que se desdobram da perspectiva neo-Schumpeteriana do desenvolvimento, não sendo algo genérico ou homogêneo, tal como implícito nas visões hegemônicas sobre o papel do Estado 
nos "fundamentos" da atividade econômica (BIRD, 1993 e 1997, por exemplo). Como primeira propriedade, o ambiente se caracteriza como um sistema, na medida em que comporta relações de interdependência, complexas e não lineares, entre agentes e instituições, que, por sua vez, são diferenciados e especializados, respondendo pelo funcionamento de partes do sistema. É o reconhecimento desta interdependência, quando referida aos espaços nacionais, que está na raiz do conceito evolucionista de sistemas nacionais de inovação, uma vez que este é definido por “... a set of institutions whose interaction determine the innovative performance... of national firms.” (Nelson \& Rosenberg, 1993, pp. 4 e 5).

Logo, o uso rigoroso do adjetivo "sistêmico" para qualificar a perspectiva evolucionista da ação estatal na dinâmica industrial, remete, necessariamente, para o conceito de sistema desenvolvido pela literatura que trata dos sistemas nacionais de inovação $0^{5}$, envolvendo tanto os fatores ligados à infraestrutura física, financeira, humana e de conhecimentos quanto os fatores relacionados a estrutura econômica e aos setores de atividade, que, em conjunto, condicionam a formulação de estratégias de inovação as firmas. Num mundo interdependente, a geração de externalidades é uma característica intrínseca à ação de todos os agentes e instituições que se relacionam, direta ou indiretamente, no processo coletivo de aprendizado, o que aponta para a necessidade de um enfoque sistêmico tal como enfatizado por Idquist (1997). Na divisão de papéis que caracteriza o sistema econômico, o Estado apresenta-se como uma instância que pode regular e promover a interação entre os agentes, considerando o poder de arbitragem que lhe é inerente e o fato de que o âmbito de sua ação deve envolver o funcionamento do sistema de inovações como um todo, permitindo, em princípio, uma visão dos requerimentos de articulação entre suas partes distintas.

Em decorrência, a política industrial deve se orientar pelo estímulo às relações interativas (competitivas e cooperativas) que se mostram mais favoráveis ao aprendizado. As concepções lineares de política econômica e o estabelecimento preciso de relações de causa e efeito entre a intervenção pública localizada e direta e as estratégias privadas devem ser superadas em favor de um padrão de intervenção mais indireto que privilegie a criação de condições ambientais favoráveis às estratégias empresariais de inovação.

No interior dos sistemas nacionais de inovação é possível identificar três tipos de interdependências que se apresentam como cruciais para as estratégias de inovação das firmas e para a transformação da estrutura produtiva, podendo ser situadas como uma preocupação específica da política industrial:

Interdependências entre as empresas nos mercados industriais particulares, relacionadas, principalmente, ao nível de rivalidade existente, mas também envolvendo relações de cooperação. Nesse âmbito, emerge a política de concorrência como

\footnotetext{
${ }^{5} \mathrm{O}$ conceito de sistemas utilizado por esta literatura é trabalhado especialmente por Nelson (1993), Nelson \& Rosenberg (1993), Lundvall (1992), Freeman (1995), Edquist (1997), Edquist \& Johnson (1997) e Clark (1991).
} 
um componente essencial da política industrial que deve se voltar tanto para o estímulo à rivalidade quanto para o fortalecimento dos competidores (Possas et alii, 1995).

Interdependências nas cadeias produtivas e tecnológicas e em grupos de atividades correlatas (software e computadores, por exemplo), que conformam os complexos industriais (do tipo insumo-produto ou do tipo tecnológico, Erber, 1992) e os distritos industriais, entre outras possibilidades de interação intersetorial. A ação sobre este conjunto de interdependências remete para as políticas de articulação industrial e de estímulo a segmentos particulares que se apresentam como elos importantes da matriz produtiva.

Interdependências com relação à infra-estrutura ${ }^{6}$ física, financeira, de recursos humanos e de C\&T, que sejam mais diretamente vinculadas aos requerimentos particulares da indústria, permitindo-se pensar em políticas de infra-estrutura focalizadas para conjuntos de atividades industriais particulares.

A segunda propriedade do ambiente competitivo refere-se à sua heterogeneidade e especificidade estrutural. É a dinâmica heterogênea e diferenciada da estrutura produtiva associada ao processo de inovação que constitui o elemento chave que dá conteúdo à noção de sistemas nacionais de inovações, condicionando o processo de aprendizado do qual participam as empresas e as instituições. Nas palavras de Lundvall (1992, pp. 9 e 10, destaque acrescentado), "If innovation reflects learning and if learning partially emanates from routine activities, innovation must be rooted in the prevailing economic structure. The areas where technical advance will take place, will primarily be those where a firm, or a national econo$m y$, is already engaged in routine activities".

Assim sendo, há um ambiente estrutural que diferencia e delimita as possibilidades e as formas de aprendizado. As estruturas econômicas nacionais são diferenciadas, uma vez que comportam setores de atividade e relações de interdependência econômica e tecnológica distintos.

Esta heterogeneidade dos ambientes nacionais, por sua vez, desdobra-se em seu interior em termos da existência de distintas lógicas evolutivas que perpassam os setores de atividade. Uma das principais contribuições evolucionistas (inclusive em relação ao próprio Schumpeter) reside na identificação destas diferenças, de acordo com os regimes (ou paradigmas) tecnológicos e estratégias competitivas vigentes, que embutem diferentes condições de oportunidade, cumulatividade e apropriabilidade tecnológica (Pavitt, 1984; Winter, 1984; Malerba \& Orsenigo, 1997; Dosi, 1988, por exemplo). O dinamismo dos sistemas nacionais apresenta-se como uma resultante da evolução desta base produtiva heterogênea e, portanto,

\footnotetext{
${ }^{6}$ Utiliza-se, neste trabalho, a ideia mais ampla de infra-estrutura, na linha sugerida por Smith (1997), envolvendo todas as áreas citadas. Conceitualmente, estas atividades se referem aos recursos de uso coletivo, de âmbito mais ou menos abrangente, cuja produção requer decisões de investimento (se distinguindo, portanto, dos recursos naturais) e que se mostram essenciais para a competitividade da indústria e para as estratégias de inovação das firmas.
} 
específica que embute diferentes potencialidades e formas de organização da atividade inovadora.

Como desdobramento desta visão estrutural, pode-se afirmar que os requerimentos ambientais (ou sistêmicos) são peculiares às características da estrutura produtiva, em termos de sua composição setorial e dos regimes tecnológicos predominantes. A ação estatal sobre o ambiente distingue-se, assim, de uma ação genérica, considerando-se a necessidade de uma atuação diferenciada, consoante com a estrutura existente e com as possibilidades de sua transformação. A vantagem competitiva nacional resulta das vantagens provenientes de um ambiente fortemente especializado, de difícil reprodução, que favorece uma determinada estrutura produtiva. $^{7}$

O ponto essencial é que a intervenção estatal deve ser, a um só tempo, sistêmica e estrutural, no sentido de que deve privilegiar a atuação estatal nas interdependências que envolvem as empresas que atuam no setor industrial e que estas interdependências são específicas às diferentes estruturas econômicas, impondo requerimentos diferenciados de competitividade. ${ }^{8}$ Descendo a análise no nível dos setores de atividade, isto significa dizer que as indústrias apresentam trajetórias evolutivas particulares que requerem condições sistêmicas distintas, em termos dos padrões competitivos e cooperativos vigentes nos distintos mercados, das relações na cadeia produtiva e tecnológica e dos aportes fornecidos pela infraestrutura física, financeira, humana e de C\&T.

Como decorrência desta visão, o setor e o mercado constituem elos analíticos imprescindíveis da análise estratégica pública e privada. O foco da ação governamental é a empresa, mas seu ambiente evolutivo mais imediato, competitivo e tecnológico, é definido no âmbito dos mercados em que esta atua. Entre a ação estatal sistêmica e a estratégia da firma coloca-se o setor como uma mediação analítica essencial enquanto um espaço privilegiado da concorrência capitalista que possui lógicas evolutivas singulares, decorrentes da especificidade do processo de aprendizado (captado, sinteticamente, pela noção de regime tecnológico - Malerba \& Orsenigo, 1997). Nesse sentido, a ação sistêmica sempre possui impactos setoriais diferenciados, mesmo quando não utiliza mecanismos mais diretos de intervenção na tradição "intervencionista" de política industrial. O Estado, na abordagem evolucionista, não pode substituir a empresa como agente da dinâmica, tendo um papel essencialmente sistêmico e, de fato, mais indireto, organizando as relações

\footnotetext{
${ }^{7}$ uma direção análoga, vide Porter (1993), cuja perspectiva converge, em muitos aspectos, com a adotada neste trabalho, uma vez que o autor segue a noção Schumpeteriana de concorrência, privilegiando a diversidade e a criação de assimetrias como a norma do processo competitivo. Na acepção deste autor, os sistemas nacionais oferecem um ambiente (que configuram, em suas palavras, o "diamante da competitividade") mais ou menos favorável às estratégias competitivas específicas às distintas indústrias.

${ }^{8}$ Adota-se neste trabalho uma noção de competitividade de corte Schumpeteriano, simplesmente como o processo de obtenção de vantagens na luta competitiva mediante a introdução de inovações, na linha proposta por Baptista (1997) e por Porter (1993, p. 6), que se aplica tanto ao nível da empresa quanto do setor ou do país.
} 
de interdependência em favor da inovação. Porém, esse poder sobre as condições sistêmicas exerce sua influência na medida em que altera os ambientes competitivos particulares nos quais as empresas estão incrustadas. ${ }^{9}$

Deve-se, portanto, ter um certo cuidado ao descartar a importância das políticas setoriais em nome de uma visão que privilegia, de um lado, o ambiente (sempre identificado como genérico e homogêneo) e, de outro lado, a empresa como o agente da dinâmica capitalista (a exemplo do que propõe Teece, $1991^{10}$ ). O reconhecimento de que o papel do Estado é indireto e que se volta, essencialmente, para as relações de interdependência entre os agentes, não significa que a análise estrutural e da lógica evolutiva dos setores de atividades torna-se prescindível, cindindo-se a ação estatal entre uma órbita sistêmica (ou dos "fundamentos" econômicos, como propõe o BIRD, 1993) que deve ser privilegiada e uma órbita setorial que deve ser abandonada. A política industrial de corte sistêmico também envolve opções (Quais medidas de promoção da concorrência são pertinentes para os diferentes grupos de indústria? Qual base de recursos humanos e nível de qualificação deve ser privilegiado? Qual conhecimento científico? Que tipo de atividade tecnológica e de formas de cooperação são mais adequadas? etc.), cuja definição deve ser efetuada à luz de uma análise dos requerimentos particulares dos setores de atividade que conformam a estrutura industrial vigente e desejada. Ou seja, mesmo que as políticas setoriais de âmbito restrito e direto (não sistêmico) sejam descartadas, em virtude de uma certa visão da divisão de papéis entre o Estado, as empresas e o mercado, a estrutura produtiva e as lógicas evolutivas setoriais que incorpora continuam como elos analíticos imprescindíveis à política industrial, uma vez que "[...] embora as empresas sejam o objeto último da política industrial, o setor em que se inserem constitui o principal elemento organizador do seu comportamento..." (Erber, 1992, p. 18).

Assim sendo, as condições sistêmicas existentes mostram-se mais ou menos adequadas ao desenvolvimento de determinadas atividades. É isto que explica, em grande medida, o fato que as vantagens competitivas das nações se expressam no âmbito de grupos específicos de indústrias, muito mais do que no nível de empresas individualizadas, como mostram Porter (1993), em seu estudo da competitividade

\footnotetext{
${ }^{9}$ Rothwell \& Zegveld (1981, p. 52 e 53) fazem uma avaliação, baseada em estudos de caso e em diversos projetos de pesquisa, de 5 das principais modalidades de intervenção governamental (demanda do Estado, subsídios, regulação, infra-estrutura tecnológica e universidades) que influenciam as inovações em diferentes setores de atividade, estabelecendo um rank de 1 a 5 , em ordem crescente de importância. Mostram que a diversidade setorial é expressiva, evidenciando a visão defendida de que o impacto das condições sistêmicas (associadas, por exemplo, ao papel das universidades ou da regulação) é setorialmente específico, mesmo quando possuem um nível de abrangência não restrito a indústrias ou segmentos produtivos particulares.

${ }^{10} \mathrm{O}$ autor é absolutamente claro no argumento: “... the basis of competitive advantage lies at the leveil of the firm, not the industry or sector. To the extent that sector-specific policies impact firms uniformly, studies exploring the determinants of firm-level performance suggest that other factors, and in particular matters of internal organisation and management, are more critical to competitiveness than are sectorspecific policies" (Teece, 1991, p: 47).
} 
de diferentes setores em países particulares, e Patel \& Pavitt (1994) ao afirmarem que, mesmo na OECD, é possível demarcar diferenças substantivas entre os padrões nacionais setoriais de capacitação e acumulação tecnológica e, portanto, de competitividade.

Em poucas palavras, numa abordagem microfundamentada e dinâmica do desenvolvimento, a influência da política industrial incide na empresa na medida em que altera seu ambiente competitivo sistêmico particular manifesto nas condições que envolvem as distintas atividades econômicas em que participa. Nessa perspectiva, a questão que se coloca para a política industrial é como influenciar a base nacional de sorte que favoreça o surgimento de um ambiente propício para a busca de estratégias inovadoras dinâmicas por parte das empresas em determinados conjuntos de atividades industriais. O corte rígido entre políticas industriais horizontais sistêmicas e verticais seletivas é, no mínimo, difuso. O enfoque relevante para a politica industrial nacional é, simultaneamente, sistêmico e estrutural.

Nesta linha de raciocínio, não há um ambiente genérico indiferenciado que seja favorável a um padrão também genérico de desenvolvimento industrial. Deve-se definir quais condições ambientais são mais favoráveis para um certo padrão de evolução da estrutura produtiva da indústria. Do ponto de vista de uma visão neoschumpeteriana microfundamentada, afirmações genérica (atualmente predominantes) que enfatizam a ação estatal nos fundamentos, a base de recursos humanos (ou "Capital Humano"), a infraestrutura geral, a estabilidade e as condições político-institucionais (BIRD, 1993 e 1997, por exemplo) são totalmente insuficientes ao separarem as condições sistêmicas do perfil evolutivo da estrutura produtiva. $\mathrm{Na}$ perspectiva aqui seguida, os "fundamentos" em si não fornecem as condições suficientes (talvez somente as necessárias), em termos de política econômica, requeridas à dinâmica de transformação estrutural.

Cabe agora indagar o papel das políticas industriais tradicionalmente consideradas como seletivas que envolvem a mobilização de instrumentos diretos de intervenção, de acordo com metas fixadas para setores particulares. Em primeiro lugar, aceita-se o relativo consenso na literatura evolucionista de que políticas intervencionistas setoriais são tanto mais necessárias quanto maior o atraso econômico de um país (Dosi et alii, 1990; Lundvall, 1994; Johnson, 1992; Baptista, 1997, por exemplo), uma vez que, nestas condições, é possível estabelecer, com certa facilidade, as atividades prioritárias a serem implementadas pelos países menos desenvolvidos em processo de catching up, a partir da existência de um referencial relativamente preciso dos paradigmas tecnológicos dominantes nos diferentes setores, que servem como um guia para a ação pública. Vale dizer, as situações de atraso vigentes nos países subdesenvolvidos ou em desenvolvimento se caracterizam pela ausência de elos centrais na estrutura produtiva e institucional, que requerem uma ação estruturante do Estado (Erber, 1992) para induzir - ou mesmo assumir a responsabilidade direta via empresas estatais - a montagem de determinados setores na matriz produtiva, envolvendo uma ruptura radical das rotinas preexistentes.

Em segundo lugar, como norma geral, as ações seletivas focalizadas sobre certas atividades ou indústrias se justificam, tanto nos casos dos países avançados 
quanto dos tardios, na medida em que possuem, elas mesmas, um desdobramento sistêmico - voltado, por exemplo, para a constituição de núcleos endógenos de progresso técnico e de dinamismo (Fajnzylber, 1983, pp. 375 e 376) - que alteram (ou preservam, no caso de ações defensivas) o ambiente competitivo em distintas atividades econômicas de um determinado conjunto interdependente de atividades. Neste sentido, e ironicamente, as políticas seletivas setoriais de corte vertical se tornam necessárias justamente quando possuem um impacto sistêmico na estrutura econômica, elevando (ou preservando) o nível das oportunidades tecnológicas existentes, sem o que dificilmente seria possível justificar a intervenção pública em atividades muito particulares e que apresentam alto risco de insucesso. As políticas setoriais, assim, devem ser subordinadas a essa lógica nacional de evolução da estrutura produtiva como um todo. Ou seja, são apenas uma parte da política industrial que se justifica quando inserida em uma visão estratégica do setor como elo essencial aos sistemas nacionais. As políticas setoriais ad hoc, descoladas de uma orientação estratégica para a estrutura produtiva como um todo, não se enquadram neste enfoque proposto.

Não obstante, mesmo nos casos em que as políticas setoriais se justificam do ponto de vista sistêmico, deve ser sublinhado que, para ser coerente com os fundamentos metodológicos evolucionistas (em particular a noção de racionalidade limitada dos agentes, a importância da variedade e da liberdade de busca e a visão do mercado como espaço seletivo), a identificação de áreas prioritárias e a mobilização dos instrumentos de política industrial devem envolver o estabelecimento de uma elevada conectividade com o setor empresarial (estabelecimento de fóruns de discussão, de arenas de coordenação por complexos tecnológicos e industriais etc.), reconhecendo-se a reduzida capacidade da burocracia pública para substituir a empresa privada e o mercado na busca e seleção de atividades essenciais, a incerteza que permeia o processo decisório e a necessidade de coerência sistêmica entre as orientações políticas. ${ }^{11}$ É a partir de uma elevada interação da política industrial com os segmentos empresariais que os riscos de insucessos e de atos voluntaristas são atenuados.

Em suma, as politicas seletivas setoriais podem constituir um dos componentes sistêmicos da política industrial e não sua antítese, ao propiciar a criação de ambientes nacionais favoráveis ao aprendizado e à inovação. Entre uma concepção estritamente setorial e uma concepção genérica que não delimita o espaço da política industrial, a proposta aqui defendida coloca a dinâmica da estrutura produtiva da indústria como o elemento analítico central que permite demarcar o âmbito próprio da política industrial, conferindo substância a uma visão sistêmica.

Isto posto, pode-se ampliar a definição de política industrial proposta no tópico anterior como o foco da intervenção pública na dinâmica de inovações da indústria, visando promover transformações qualitativas na estrutura produtiva e o desenvol-

\footnotetext{
${ }^{11}$ Por exemplo, políticas setoriais que reduzam a rivalidade competitiva entre as empresas por longos períodos tendem a apresentar resultados precários em termos dos esforços de inovação das firmas.
} 
vimento das economias nacionais, mediante ações sistêmicas que alteram, seletivamente, os ambientes competitivos em que se formam as estratégias empresariais.

\section{DIMENSÃO TEMPORAL DA POLÍTICA INDUSTRIAL E CONCEITOS DE EFICIÊNCIA}

O objetivo da política industrial de promover o dinamismo da atividade industrial, mediante a geração e absorção de inovações, coloca ainda a necessidade de se pensar os conceitos de eficiência que definem os critérios normativos que devem nortear a intervenção pública.

De acordo com a perspectiva neo-Schumpeteriana, foi visto que a política industrial deve atuar sobre o ambiente que condiciona as estratégias de inovação das firmas (incluindo as voltadas para a absorção de tecnologia). O mercado aparece como um espaço de competição em torno da criação e da seleção de inovações, estando na base da disseminação do progresso técnico no sistema econômico, mediante os processos de difusão de tecnologias superiores na estrutura produtiva. As atividades de busca e o processo de seleção, como as duas forças dinâmicas da expansão capitalista (Nelson \& Winter, 1982), constituem os fundamentos dos critérios de avaliação do funcionamento dos mercados. Um mercado que gera variedade num ritmo intenso e que seleciona tecnologias superiores, difundindo-as mais rapidamente, é um mercado eficiente (Metcalfe, 1995). Portanto, em termos mais gerais, a noção de eficiência neo-Schumpeteriana é a eficiência para a mudança, seja para inovar ou para absorver as inovações superiores existentes no mercado.

Descarta-se, assim, de forma radical, o conceito de eficiência estática (alocativa ou distributiva), mesmo como critério para políticas industriais voltadas para o curto prazo, uma vez que o mercado é o espaço da dinâmica, do processo de inovação e de seleção. ${ }^{12}$ Como já colocado de forma incisiva pelo próprio Schumpeter (1985, capítulo 7), em sua análise das práticas monopolistas, não é pela sua função de minimizar custos e preços de uma dada estrutura que o mercado deve ser avaliado; mas sim por seu dinamismo na geração e difusão de inovações que alteram as condições estruturais a partir das quais os preços são formados. ${ }^{13}$ Deste modo, o impacto do mecanismo de mercado no bem-estar é indireto, ao permitir o acesso a produtos com custos inferiores (independentemente da distribuição de renda - Dosi et alii, 1990) e/

\footnotetext{
12 Para uma síntese da perspectiva Schumpeteriana e dos conceitos de eficiência vide Possas et alii (1995, pp. 28, 29 e 30), que identificam cinco acepções distintas, a saber: eficiência produtiva, alocativa, distributiva, dinâmica e seletiva.

${ }^{13}$ Nesta mesma direção, também devem ser questionadas as visões de eficiência e de política industrial, pretensamente heterodoxas, baseadas na teoria dos mercados contestáveis (Baumol et alii, 1982 e Araújo Júnior, 1993 e 1997), que privilegiam seu impacto na minimização de custos e de preços, tratando-se os casos de regulação da concorrência em mercados imperfeitamente contestáveis, de apoio às atividades infantes e às indústrias em declínio como situações excepcionais (à semelhança das falhas de mercado tipicamente neoclássicas).
} 
ou qualidade superior e, principalmente, como propulsor das estratégias de inovações que estão na raiz dos processos de desenvolvimento a longo prazo. A ligação entre o ambiente competitivo e o comportamento da estrutura de custos e de preços é mediada pelo impacto daquele na geração e disseminação de inovações.

Para efeito normativos mais concretos, é útil desdobrar o conceito Schumpeteriano de eficiência numa dimensão de curto prazo, vinculada aos processos evolutivos a partir da estrutura produtiva e tecnológica existente nos sistemas nacionais, e numa outra, de longo prazo, relacionada aos processos de busca por mudanças mais profundas na estrutura produtiva relacionadas ao desenvolvimento de novas atividades econômicas e novos paradigmas tecnológicos. Essas duas dimensões são dinâmicas no sentido de que se vinculam a processos de mudanças que ocorrem ao longo do tempo, de forma ininterrupta e endógena ao processo competitivo, referindo-se, no primeiro caso, ao dinamismo do mercado para promover melhorias e inovações incrementais, determinando a competitividade presente dos agentes, e, no segundo caso, às mudanças para novos universos tecnológicos (ou paradigmas), que determinam a evolução futura no nível de oportunidade tecnológica e da competitividade dos sistemas nacionais. A ideia de eficiência apresenta se, assim, tanto como uma expressão da capacidade empresarial de evoluir no interior das trajetórias tecnológicas que emanam da base produtiva existente num determinado período (aperfeiçoando os trade offs dos paradigmas vigentes) quanto de sua capacidade estratégica para se posicionar com vistas ao futuro na introdução de novos paradigmas e novas atividades econômicas.

Do ponto de vista da política industrial, essa distinção entre a eficiência de uma dada estrutura e a associada à mudança estrutural mais profunda remete para a existência de dois horizontes temporais da estratégia pública que devem ser trabalhados simultaneamente. No curto prazo, o critério normativo da política industrial vincula-se - como uma aproximação, dinâmica, dos conceitos de eficiência usualmente utilizados - à obtenção de eficiência produtiva, enquanto um critério que permite aferir a competitividade da estrutura existente, fruto da capacidade empresarial para se posicionar favoravelmente frente ao "estado-da-arte" mundial, expressando-se em termos das vantagens competitivas em custos e da qualidade e diversidade da linha de produtos ofertados rotineiramente. Essa ideia de eficiência produtiva não se restringe apenas à noção usual de eficiência técnica determinada do ponto de vista dos processos de produção utilizados. Por trás da eficiência produtiva constatada por indicadores diversos de competitividade (custos, qualidade, índices de perdas, durabilidade e confiabilidade, etc.), há uma dinâmica seletiva que depende da capacidade dos agentes de seguir trajetórias de inovações incrementais e de superar as barreiras, tácitas ou formais, de apropriabilidade para acompanhar, ao longo do tempo, a evolução do estado-da-arte mundial nos distintos setores de atividade. ${ }^{14}$

\footnotetext{
${ }^{14}$ Nesta linha de argumentação, Smith (1991) afirma que mesmo no curto prazo sempre é possível fazer melhor, somente cabendo uma visão dinâmica do processo capitalista. Na literatura recente sobre as novas abordagens administrativas também se enfatiza que as empresas nunca atingem um resultado
} 
No longo prazo, o critério normativo da política industrial relaciona-se à obtenção de eficiência dinâmica (em sentido mais restrito, vinculado a um horizonte temporal mais amplo do que o envolvido na eficiência produtiva), que se refere ao esforço de inovação dos agentes, setores e sistemas nacionais para construir as bases endógenas da acumulação tecnológica no futuro, buscando novas atividades e novos paradigmas que permitam elevar o nível de oportunidade tecnológica a longo prazo e superar o risco de aprisionamento (lock in) nas bases de capacitação preexistentes. Aqui também se verifica uma dinâmica seletiva, no qual os agentes e sistemas nacionais conseguem ou não alterar o seu perfil de especialização para os novos paradigmas e atividades de maior oportunidade e potencial de crescimento, aliada a uma dinâmica criativa, determinada pelo seu esforço para buscar novos horizontes, rompendo com os limites da base de conhecimento e de aprendizado existentes.

Isto posto, pode-se concluir que a política industrial possui como objetivos tanto o favorecimento da constituição de um ambiente de competição indutor da eficiência produtiva quanto o estímulo para a construção de bases sistêmicas que induzam a busca de eficiência dinâmica. ${ }^{15}$ "Esta última dimensão da eficiência apresenta-se como dominante para a evolução de longo prazo dos sistemas nacionais, uma vez que é a partir do acerto nas apostas estratégicas que a eficiência da estrutura produtiva resultante se reverterá ou não num elevado dinamismo nas trajetórias nacionais de desenvolvimento. ${ }^{16}$

Assim sendo, o corte temporal utilizado permite descartar qualquer referência à estática, mesmo quando se trata de políticas industriais voltadas para o curto prazo. $\mathrm{Na}$ acepção defendida, a política industrial constitui uma dimensão dinâmica da política pública, quer seja quando se volta para os incrementos progressivos na competitividade dos agentes e estruturas existentes, quer seja quando se volta para induzir estratégias inovadoras mais radicais. A perspectiva da inovação (seja tecnológica, organizacional ou estratégica) e da alteração ou ruptura das rotinas preexistentes constitui o norte da política industrial em sua dimensão de curto ou de longo prazo. Deste modo, ideias dinâmicas como as de estímulo à busca de

ótimo e que as melhorias sempre são possíveis e devem ser buscadas como mecanismo essencial da competitividade (Deming, 1990). Isto significa que as políticas industriais vinculadas à obtenção de eficiência produtiva devem considerar tanto a situação dos agentes frente ao estado-da-arte em um determinado momento quanto sua capacidade de evolução mediante a introdução permanente de melhorias nos processos e produtos ofertados.

${ }^{15}$ Rothwell (1986) faz uma distinção análoga entre duas dimensões da política industrial, definindo uma dimensão estratégica e uma dimensão tática. Segundo este autor (p. 108), os instrumentos inerentes a uma dimensão estratégica "are of long-term perspective and are concerned with stimulating the emergence of new or sunrise industries and with inducing major structural industrial shifts". Os instrumentos táticos da política industrial, por sua vez, "are concerned with improving the innovatory potential of existing firms and upgrading product quality and manufacturing productivity”.

${ }^{16}$ Nesta direção, Porter (1993, p. 695) alerta que "políticas que trazem vantagens de custos de curto prazo, estáticas, mas que inconscientemente enfraquecem a inovação e o dinamismo, representam o erro mais comum e profundo na política do governo para a indústria” 
atividades de maior potencial de geração de retornos crescentes, ao incremento da qualidade, produtividade e competitividade e de reestruturação industrial, entre muitas outras associadas às inovações (incrementais ou radicais) não podem ser vistas como momentos excepcionais da política industrial, mas sim como sua norma, seu hábitat natural. Por fim, cabe ainda um comentário referente ao tradicional trade off entre a eficiência estática e a dinâmica, redefinidas de acordo com os conceitos sugeridos neste trabalho em termos da eficiência produtiva e da eficiência dinâmica. Na literatura neo-Schumpeteriana, este trade off aparece de duas formas distintas. Na primeira, mais tradicional e partindo diretamente de Schumpeter (1985), coloca-se o trade off entre a eficiência em preços e os esforços de inovação (Nelson \& Winter, 1982, cap. 14), uma vez que estes últimos estão associados à obtenção de quase rendas como o incentivo essencial. Deve-se ressalvar que a eficiência produtiva, da forma dinâmica em que foi definida, já pressupõe a existência de estímulos constantes à melhoria e à diferenciação entre os agentes, não se associando à prática de preços num nível normal (no sentido neoclássico do termo). Uma empresa ou indústria produtivamente eficiente é aquela mais capacitada para introduzir e absorver melhorias que lhe permitam ofertar a preços mais baixos (ou produtos com qualidade superior) do que os concorrentes e, ainda assim, obter ganhos superiores, seja na forma de margem de lucro ou de crescimento do mercado.

$\mathrm{Na}$ segunda forma, mais particular ao referencial evolucionista, o trade off expressa o potencial aprisionamento dos agentes e dos sistemas nacionais em seu perfil pretérito de especialização, o que possui efeitos em termos de seu dinamismo no futuro. Dosi et alii (1990, capítulos 8 e 9) expressam este trade off em termos da eficiência alocativa estática Ricardiana contraposta à eficiência Schumpeteriana de inovação e à eficiência keynesiana de crescimento, sendo tanto mais acentuado quanto maior o atraso econômico dos países. Pode-se explicar isso pelo fato dos países menos desenvolvidos se especializarem em atividades com menor oportunidade tecnológica e requerimentos sistêmicos menos complexos, sendo difícil a diversificação para outras atividades. Em síntese, existe a possibilidade de que os sinais presentes de lucratividade intersetorial levem as empresas e os sistemas nacionais a ficarem presos em suas trajetórias, havendo uma especialização - inclusive do ambiente econômico - em atividades pouco dinâmicas a longo prazo. Nesse sentido, a eficiência produtiva de curto prazo poderia ser danosa para a eficiência dinâmica a longo prazo. ${ }^{17}$

Não obstante sua relevância, este trade off deve ser trabalhado com um certo cuidado. A tensão entre a competitividade presente e a futura é inerente a um sistema submetido a rendimentos crescentes cumulativos, a irreversibilidades e a padrões comportamentais rotineiros socialmente construídos, não sendo específica a

\footnotetext{
${ }^{17}$ Essa questão, com outros termos, sempre esteve presente na tradição desenvolvimentista da CEPAL, como argumento de defesa da industrialização nacional, a despeito da maior eficiência relativa das atividades agrícolas e das baseadas em recursos naturais. Na linguagem mais recente, esta dicotomia se expressa na diferença entre as vantagens comparativas estáticas e as dinâmicas.
} 
situações de atraso ou de catching $u p$. A readequação do perfil de especialização deve se constituir numa preocupação permanente para os formuladores das estratégias públicas e privadas. Faz parte dos requerimentos de um Estado comprometido com políticas de inovação a construção de capacitações dinâmicas para promover a busca do novo.

A orientação da política industrial não necessariamente deve optar por uma das dimensões da eficiência em detrimento da outra, uma vez que a administração de trade offs é inerente à política econômica. A ênfase na eficiência produtiva somente se impõe como uma barreira absoluta à busca de eficiência dinâmica se as estratégias públicas e privadas forem míopes (Bell \& Pavitt, 1993) e condicionadas por um ambiente competitivo (incluindo as políticas governamentais) que privilegie apenas os ganhos de curto prazo associados à eficiência produtiva. ${ }^{18}$ Uma política industrial de inspiração neo-Schumpeteriana, que se paute por uma visão estratégica, deve privilegiar tanto a eficiência produtiva quanto a eficiência dinâmica, constituindo-se em duas vertentes de uma estratégia competitiva mais geral para a elevação do potencial inovador e, portanto, da competitividade dos sistemas econômicos nacionais. ${ }^{19}$

Ao invés de refletir uma postura voluntarista e pouco viável, esta articulação da dimensão de curto prazo com a de longo prazo da política industrial pode apresentar impactos complementares virtuosos. Estímulos para a elevação da competitividade da linha de produtos das empresas podem favorecer mudanças mais profundas, desde que acoplados a outras ações de caráter mais estratégico, considerando que os investimentos em inovações tendem a ser tanto maiores quanto maiores forem o dinamismo da renda e dos lucros provenientes de uma elevação na eficiência produtiva. Neste sentido, uma das funções centrais de um Estado comprometido com a inovação é a de promover a fuga do lock in, estimulando a constituição de um ambiente que forneça sinais de rentabilidade para a busca de novos horizontes tecnológicos pelos agentes. Ou seja, a eficiência produtiva da estrutura existente pode apresentar-se como um elemento favorável à mudança estrutural, se houver um ambiente propício às atividades empresariais de busca de inovações mais substantivas. Talvez a principal "arte" de uma política neo-Schumpeteriana seja a de promover a competitividade presente, estimulando, ao mesmo

\footnotetext{
${ }^{18}$ Os programas de competitividade mais em voga - como os introduzidos no Brasil no início dos anos 90 - tendem a enfatizar a diretriz de exposição abrupta da indústria à competição internacional como um meio para elevação da competitividade a curto prazo, relegando a um segundo plano os objetivos de capacitação tecnológica, reforçando o conflito entre a eficiência produtiva e a dinâmica.

${ }^{19}$ A dicotomia entre a eficiência da estrutura existente e a relacionada às mudanças estruturais mais profundas também decorre dos interesses políticos hegemônicos vinculados aos padrões de especialização vigentes nos sistemas nacionais. Nesse sentido, a questão é muito mais complexa do que os limites associados à estrutura herdada e às rigidezes das rotinas e das estratégias. Há, assim, uma base política para o comportamento conservador que constitui, de fato, um elemento essencial que está por trás da dicotomia entre a eficiência produtiva e a dinâmica. Portanto, a política industrial, sobretudo na dimensão estratégica, depende fundamentalmente da base de sustentação do poder político do Estado para promover mudanças mais profundas.
} 
tempo, a busca de novas oportunidades para o futuro, tomando-se como uma premissa a constatação de que não se evita o aprisionamento da evolução futura da estrutura produtiva mediante a precarização de sua competitividade no presente.

\section{CONSIDERAÇÕES FINAIS}

As seguintes considerações permitem explicitar aspectos metodológicos e teóricos da visão apresentada e apontar alguns de seus desdobramentos principais:

1 - O referencial das falhas de mercado que norteia a visão hegemônica que justifica a ação estatal deve ser recusado. Certamente, no sentido fraco do termo, a justificativa para a ação do Estado sempre se baseará numa necessidade não suprida sem sua presença. Todavia, no corpo da teoria econômica, a noção de falhas de mercado decorre de uma visão de que o mercado possui o atributo natural de gerar estados ótimos e que somente situações anômalas ao seu funcionamento normal justificam a ação pública. Na perspectiva defendida, o mercado é o espaço competitivo institucional de busca do lucro, não possuindo atributos naturais vinculados ao desenvolvimento ou ao bem-estar (Possas et alii, 1995), decorrentes de uma forma particular e improvável de organização (o mercado competitivo neoclássico).

E mais, num mundo interdependente, qualquer subsistema isolado apresenta falhas que dependem do funcionamento de outros subsistemas. Portanto, no sentido fraco e tautológico do termo, se poderia dizer que o Estado atua nas falhas de mercado, que este último, por sua vez, atua nas falhas de governo, que as instituições de C\&T atuam nas falhas de outros tipos de instituições de desenvolvimento tecnológico e, assim, sucessivamente. Logo, a percepção do papel do Estado na dinâmica industrial deve passar pela demarcação das características particulares dos distintos agentes e instituições presentes no sistema econômico - que também podem variar ao longo do tempo e no espaço -, prescindindo-se, totalmente, de uma visão do mercado como o locus do equilíbrio e da otimização que fundamenta o conceito forte das falhas de mercado. Abre-se, deste modo, um leque importante de pesquisa institucional e histórica para subsidiar as concepções de política industrial em situações concretas, totalmente distinto do programa convencional neoclássico.

2 - A concorrência ocupa um espaço central, teórico, metodológico e normativo, em toda a argumentação desenvolvida. São nos espaços competitivos concretos que as estratégias empresariais de inovações são formuladas, gerando a transformação estrutural e as trajetórias de desenvolvimento. Portanto, é a partir da forma como as instituições interferem nos espaços da concorrência, elevando a rivalidade ou beneficiando estratégias inovadoras, que as inovações são estimuladas ou restringidas. Como desdobramento, as estruturas econômicas, caracterizadas por um certo conjunto de atividades, embutem formas particulares de concorrência que selecionam tanto regimes e trajetórias tecnológicas quanto formatos organizacionais e instituições que se mostram favoráveis às estratégias empresariais de inovações e, logo, à transformação estrutural e ao desenvolvimento. 
Por conseguinte, pensar política industrial é pensar a relação entre a ação do Estado, a concorrência e o progresso técnico. É por intermédio da ação do Estado nos ambientes da concorrência que se pode induzir as empresas privadas a perseguirem certas estratégias de introdução ou absorção de inovações. Pode-se mesmo dizer que, em última instância, todas as políticas sistêmicas (desde a política da concorrência stricto sensu até as políticas especializadas de infraestrutura tecnológica, de recursos humanos, física e financeira, além da política de articulação industria ${ }^{20}$ ) constituem vertentes essenciais da política industrial na medida em que interferem, de forma particularizada, nos ambientes competitivos em que as empresas estão imersas, condicionando suas estratégias de inovação.

A relação entre política industrial e inovações é mediada pela concorrência capitalista. Ou seja, numa economia de mercado assentada na empresa privada, o Estado interfere na dinâmica das inovações na medida em que interfere nos ambientes competitivos que caracterizam os distintos mercados. $\mathrm{O}$ aprendizado e a inovação no sistema capitalista são resultado do enfrentamento entre os capitais que, em certos momentos, podem inclusive cooperar, de sorte a elevar o seu potencial competitivo -, sendo este o âmbito em que a política industrial pode interferir no processo de geração e difusão de inovações, criando oportunidades (sistema de financiamento adequado, infraestrutura de C\&T e de recursos humanos etc.) e ameaças (política de concorrência stricto sensu) que condicionam as estratégias empresariais.

Concluindo, a concorrência constitui o processo social que gera a evolução no sistema capitalista, pois é neste âmbito que se gestam as trajetórias de inovação. ${ }^{21}$ Constitui, portanto, a dimensão central e mais abrangente para se pensar política industrial, uma vez que a ação do Estado interfere no desenvolvimento, na medida molda, direta ou indiretamente, o ambiente que permeia a concorrência capitalista. Assim sendo, a influência do Estado no fortalecimento da capacidade competitiva (ou de inovação) dos agentes e sua interferência no grau de rivalidade aparecem como os fatores centrais a serem considerados, simultaneamente, para a concepção de uma política industrial em realidades concretas. Pouco importa se as condições de concorrência são mais próximas ou não do mercado competitivo neoclássico; mas sim, em que medida são favoráveis às estratégias empresariais de inovação.

3 - A ideia de que o impacto da política industrial é condicionado pela estrutura econômica existente e desejada significa que existem padrões evolutivos de inovação específicos e comuns aos diferentes grupos de setores que conformam as estruturas industriais. Ou seja, a despeito de não ser condizente com o referencial metodológico evolucionista a existência de orientações genéricas de política econômica válidas para qualquer contexto estrutural e momento histórico, existem

\footnotetext{
${ }^{20}$ Sobre as diversas políticas que constituem parte de uma política industrial de corte sistêmico, vide Gadelha, 1999.

${ }^{21}$ Essa visão da concorrência remonta aos trabalhos de Schumpeter (1985, onde é mais explícito) e Marx (1983).
} 
regularidades no processo de aprendizado que permitem pensar a política pública num nível teórico que, por definição, requer algum nível de generalidade. ${ }^{22}$

Por conseguinte, é possível pensar certas regularidades de política industrial para grupos particulares de atividades e para estruturas produtivas que apresentam composições setoriais particulares. O referencial desenvolvido abre, assim, uma perspectiva de investigação que aponta para a possibilidade de se estabelecer regularidades normativas associadas às diferentes estruturas produtivas e aos projetos nacionais para seu desenvolvimento.

Como desdobramento dessa ideia, a perspectiva estruturalista do desenvolvimento e do papel do Estado pode ser retomada, assentando-se em bases microeconômicas mais sólidas. À perspectiva de ruptura analítica com o paradigma neoclássico se acopla uma ruptura normativa que reintroduz o papel do Estado à luz do impacto de suas ações sistêmicas na mudança estrutural.

4 - Por fim, deve ser enfatizado que uma política industrial de corte evolucionista pressupõe um "Estado flexível, comprometido com os processos de mudança e com uma elevada capacidade de análise estratégica que lhe permita observar os avanços que acontecem alhures e promover um ambiente favorável à exploração do novo. A reestruturação das formas convencionais de intervenção do "Estado talvez constitua o maior pressuposto da análise desenvolvida, representando uma frente de pesquisa essencial. A concepção sistêmica e estrutural de política industrial pressupõe um padrão de intervenção estatal muito distinto do observado nas situações histórico-concretas presentes, sobretudo nos países em desenvolvimento ou subdesenvolvidos. Supõe, entre outros requerimentos, um padrão mais indireto e complexo de intervenção, considerando que existem múltiplas frentes que precisam ser articuladas, num processo em que os resultados são lentos e demandam persistência. Os requerimentos de conectividade com a sociedade também são muito maiores. A política industrial, de fato, deve constituir um locus de articulação do "Estado com a sociedade em torno dos interesses da inovação e da transformação estrutural, o que sempre envolve resistências de toda natureza. Intervir nas inovações pressupõe uma capacidade de análise estratégica e de prospecção e uma alta conectividade com a sociedade para identificar as perspectivas do futuro, para lidar com as estruturas do passado e para rever, a cada momento, as estratégias de política econômica. Nessa perspectiva, emerge o corte mais profundo com os enfoques liberais e neoliberais dominantes: a recuperação da capacidade de intervenção e de análise estratégica do "Estado coloca-se como uma necessidade e mesmo uma pré-condição para a efetividade de uma política industrial, uma vez que, seguindo o enfoque metodológico evolucionista, as características do agente decisório condicionam suas escolhas e as ações que podem ser implementadas com sucesso.

\footnotetext{
${ }^{22}$ Tais regularidades são captadas nas noções de paradigmas e regimes tecnológicos, desenvolvidas por Dosi (1984) e Nelson \& Winter (1982).
} 


\section{REFERÊNCIAS BIBIOGRÁFICAS}

ARAÚJO Junior, J. T. (1993) “The scope for industrial policy in a free trade environment”. Texto para Discussão no 297. Instituto de Economia/ UFRJ.

ARAÚJO Junior, J. T. (1997) “Política industrial e globalização”. Seminário Brasil-Reino Unido. Rio de Janeiro, mimeo.

BAPTISTA, M. A. C. (1997) A Abordagem Neo-Schumpeteriana: Desdobramentos Normativos e Implicações para a Política Industrial. Tese de Doutorado, Instituto de Economia da Unicamp. Campinas, mimeo.

BAUMOL, W. J.; PANZAR, J. C.; e WILLIG, R. D. (1982) Contestable Markets and the Theory of Industry Structure. Orlando: HBJ.

BILL, M. \& PAVITT, K. (1993) "Technological accumulation and industrial growth: contrast between developed and developing countries". Industrial and Corporate Change 2 (2).

BIRD (1993) The East Asian Miracle: Economic Growth and Public Policy. New York: Oxford University Press.

BIRD (1997) The State in a Changing World. World Development Report. New York: Oxford University Press.

CHANG, H. J. (1994) The Political Economy of Industrial Policy. New York: St. Martin Press.

CLARK, N. (1991) "Organisation and information in the evolution of economic systems". In: Saviotti, P. P. \& Metcalfe J. S. (eds) - Evolutionary Theories of Economic and Technological Change: Present Status and Future Prospects. Chur: Harwood Academic Publisher.

CORDEN, W. M. (1980) "Relationships between macroeconomic and industrial policies". The World Economy 3 (2), p. 167-184, September.

DEMING, W. E. (1990) Qualidade: A Revolução da Administração. Rio de Janeiro: Marques Saraiva (edição original de 1982, com o título "Out of the Crisis").

DINIZ, E. (1997) Crise, Reforma do Estado e Governabilidade. Rio de Janeiro: Fundação Getúlio Vargas.

DOSI, G. (1984) Technical Change and Industrial Transformation. London: MacMillan.

DOSI, G. (1988) “Sources, procedures and microeconomic effects of innovation". Journal of Economic Literature 26, september.

DOSI, G.; PAVITI, K. \& SOETE, L. (1990) The Economics of Technical Change and International Trade. London: Harvester Wheatsheaf

EDQUIST, (1997) "System of innovation approaches: their emergence and characteristics". In: Edquist, C. (ed.) - Systems of Innovation: Technologies, Institutions and Organizations. London, Washington: Pinter.

EDQUIST, C. \& Johnson, B. (1997) “Institutions and organizations in system of innovation”. In: Edquist, C. (ed.) - Systems of Innovation: Technologies, Institutions and Organizations. London, Washington: Pinter.

ERBER, F. (1992) “Desenvolvimento industrial e tecnológico na década de 90 - uma nova política para um novo padrão de desenvolvimento”. Ensaios FEE, 13 (1), 9-42. Porto Alegre.

FAJNZYLBER, F. (1983) La Industrialización Trunca de América Latina. México: Editorial Nueva Imagen.

FREEMAN, C. (1995) - "The national system of innovation in historical perspective". Cambridge Journal of Economics 19.

GADELHA, C. A. G. (1999) Desenvolvimento e Política Industrial: uma Visão Neo-Schumpeteriana Sistêmica e Estrutural. Tese de Doutorado, Instituto de Economia da Universidade federal do Rio de Janeiro. Rio de Janeiro, mimeo.

JOHNSON, B. (1992) “Institutional learning”. In: Lundvall, B.(ed.) - National Systems of Innovation. Toward a Theory of Innovation and Interactive Learning. London: Pinter.

LUNDVALL, B. (1992) “Introduction”. In: Lundvall, B.(ed.) - National Systems of Innovation. Toward a Theory of Innovation and Interactive Learning. London: Pinter.

LUNDVALL, B. (1994) "Innovation policy in the learning economy". Paper presented at the international seminar on policies for technological development organised by CIDE. Mexico City, 24 of january. Mimeo. 
MALERBA, F. \& ORSENIGO, L. (1997) “Technological regimes and sectoral patterns of innovative activities". Industrial and Corporate Change 6 (1), 83-117.

MARX, K. (1983) O Capital: Crítica da Economia Política. São Paulo: Abril Cultural (Coleção: “Os Economistas").

MARTINS, L. (1995) “Crise de poder, governabilidade, governança.” In: Velloso, J. P. R. Cavalcanti de Albuquerque, R. - Governabilidade \& Reformas. Fórum Nacional. Rio de Janeiro: José Olympio.

METCALFE, J. S. (1995) “The economic foundations of technology policy: equilibrium and evolutionary perspective". In: Stoneman, P. - Handbook of the Economics of Innovation and Technological Change. Oxford/UK and Cambridge/USA: Blackwell.

MOWERY, D. C. (1995) Science and Technology Policy in Interdependent Economies. Boston, Dodrecht and London: Kluwer Academic Publisher.

NELSON, R. R. (1993) “A retrospective” (Chapter 16). In: Nelson, R. R. (ed.) (1993) - National Innovations Systems. A Comparative Analysis. New York, Oxford: Oxford University Press.

NELSON, R. R. \& WINTER, S. G. (1982) An Evolutionary Theory of Economic Change. Cambridge, Mass: Harvard University Press.

NELSON, R. R. \& ROSENBERG, N. (1993) “Technical innovation and national systems”. In: Nelson, R. R. (ed.) (1993) - National Innovations Systems. A Comparative Analysis. New York/ Oxford: Oxford University Press.

OECD (1992) Industrial Policy in OECD Countries. Annual Review. Organisation for Economic Cooperation and Development.

OSTRY, S. \& NELSON, R. R. (1995) Techno-Nationalism and Techno-globalism: Conflict and Cooperation. Washington: The Brookings Institutions.

PAVITT, K. (1984) "Sectoral pattern of technical change: toward a taxonomy and a theory". Research Policy 13 (6).

PATEL, P. \& PAVITT, K. (1994) "Uneven (and divergent) technological accumulation among advanced countries: evidence and a framework of explanation". Industrial and Corporate Change 3(3).

PORTER, M. L (1993) A Vantagem Competitiva das Nações. Rio de Janeiro: Campus (edição original de 1990).

POSSAS, M. L.; FAGUNDES, J.; e PONDÉ, J. L. (1995) "Política antitruste: um enfoque schumpeteriano". Textos para Discussão n 347 , Instituto de Economia /UFRJ.

ROTHWELL, R. (1986) "Technological change and reindustrialization: in search of a policy framework". In: Jerry Dener (coord.) - Competitiveness Through Technology. Lexington Books.

ROTHWELL, R. \& ZEGVELD, W. (1981) Industrial Innovation and Public Policy: Preparing for the 1980s and the 1990s. London: Pinter.

SCHUMPETER, J. (1985) Capitalismo, Socialismo e Democracia. Rio de Janeiro: Zahar.

SOETE, L. (1991) "National support policies for strategic industries: the international implications." In: OECD - Strategic Industries in a Global Economy: Policy Issues for the 1990s. OECD International Futures Programme.

SMITH, K. (1991) "Innovation policy in an evolutionary context." In: Saviotti, P. P. \& Metcalfe, J. S. (eds.)-Evolutionary Theories of Economic and Technological Change: Present Status and Future Prospects. Chur: Harwood Academic Publisher.

SMITH, K. (1997) “Economic infrastructure and innovation systems.” In: Edquist, C. (ed.) - Systems of Innovation: Technologies, Institutions and Organizations. London, Washington: Pinter.

SUZIGAN, W. \& VILLELA, A. V. (1997) Industrial Policy in Brazil. Campinas: Editora da Unicamp.

TEECE, D. J. (1991) "Support policies for strategic industries: impact on home economies". In: OECD - Strategic Industries in a Global Economy: Policy Issues for the 1990s. OECD International Futures Programme.

WINTER, S. G. (1984) “Schumpeterian competition in alternative technological regimes". Journal of Economic Behaviour and Organisation 5, 287-320. 